\title{
Sobre un posible sentido de la invocación al Aér en Nubes de Aristófanes
}

\author{
Daniel GUTIÉRREZ \\ Universidad de Buenos Aires \\ almejasapera@yahoo.com.ar
}

Recibido: 3-02-2013

Aceptado: 6-12-2013

\section{RESUMEN}

En la comedia Nubes, del poeta cómico Aristófanes, se invoca tres veces al Aér $r$ dos veces lo hace Sócrates y una Strepsiádes. Los traductores, comentaristas y críticos siempre han considerado que, en la mención de este elemento, están aludidas las doctrinas cosmológicas de los filósofos de la phýsis, especialmente del physikós Diógenes de Apolonia. Según los testimonios de Platón, Sócrates habría desarrollado, paralelamente o incluso con preferencia a la actividad filosófica, la práctica de la espiritualidad, ejercitando y desarrollando técnicas del control y concentración de la respiración. Nubes también ofrece testimonios para dilucidar este aspecto de la personalidad histórica de Sócrates.

Palabras clave: Sócrates, Nubes, Aire, respiración, ejercicio espiritual.

\begin{abstract}
In the comedy The Clouds, from the comic poet Aristophanes, the Aér is mentioned three times, twice by Socrates and one by Strepsiades. Translators, commentators and critics have always considered that when this element was mentioned, it referred to the cosmological doctrines of the philosophers of the phýsis, especially of the physikós Diogenes of Apolonia. According to the testimonies of Plato, Socrates would have developed, at the same time or even with preference to the philosophical activity, the practice of spirituality, exercising and developing control and breathing concentration techniques. The Clouds also offers testimonies to elucidate this aspect of Socrate's historic personality.
\end{abstract}

Keywords: Socrates, The Clouds, Air, breathing, spiritual exercise.

I. La primera invocación que hace Sócrates en Nubes es bastante llamativa. En un

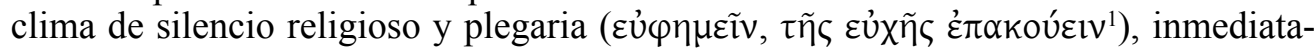
mente posterior a lo que puede ser considerado un rito de iniciación ${ }^{2}$, invocando a sus

\footnotetext{
${ }^{1}$ Cfr. Ar. Nu., v. 263. Las abreviaturas de autores antiguos y sus obras serán citados según LSJ.

${ }^{2}$ De diversas maneras se ha interpretado el carácter de este rito iniciático en Nubes: ya como pitagórico (Gil, 1967: 56; Melero, 1971: 429), ya como eleusino (Adkins, 1970: 13-15; Marianetti, 1993: 23), ya como órfico (Gelzer, 1956: 67; Sarri, 1973: 542-3).
} 


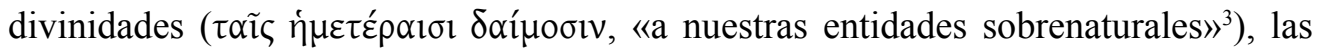
Nubes, aparece en primer lugar, curiosamente, invocado el Aire, en segundo lugar el Éter y finalmente las Nubes. La tradición ha interpretado que la mención del elemento aéreo en esta invocación y en otros pasajes de la comedia no iba más allá de la referencia a los filósofos de la phýsis, especialmente a Diógenes de Apolonia, a los que Aristófanes habría parodiado y condenado por introducir divinidades distintas de las del culto tradicional y, por eso, factor de corrupción de las creencias religiosas. Es muy probable que en esta comedia que no haya más que una alusión a esas doctrinas «científicas» que comenzaron a surgir en la cultura griega a partir de los physikoi jonios. Incluso uno de ellos, Anaxímenes, sostenía que Aér era la arkhé primordial mediante la cual puede ser explicado lo real. No obstante, por lo que se ha testimoniado de Sócrates $^{4}$, sobre todo por la tradición que parte de Platón, se puede explicar esta primacía de la invocación al Aér como representado la actividad de Sócrates en tanto practicante de su peculiar modo de vida basado en ejercicios espirituales. La hipótesis que guía este trabajo se basa, pues, en la creencia de que Sócrates, antes que filósofo, antes que dialéctico, antes que «científico», fue principalmente, un phrontistés, un meditador, y un epimele $\underline{\text { és, }}$, un practicante de la espiritualidad.

II. La figura de Diógenes de Apolonia habría resultado interesante para un comediógrafo y facilitado sus efectos paródicos ${ }^{5}$, puesto que en la exposición de su sistema se evidencia que configuró su pensamiento mediante una yuxtaposición de las doctrinas anteriores esforzándose por «hacer una "versión renovada" de los antiguos sistemas jonios ${ }^{6}$, pues combina y aprovecha eclécticamente: i) el Aire, en tanto elemento primordial (como lo había afirmado Anaxímenes), ii) el monismo de Anaxágoras, iii) el principio de que lo diferente no puede actuar sobre lo diferente (por lo que niega el sistema de Empédocles), iv) el concepto de vacío (como lo habían hecho los atomistas Leucipo y Demócrito) y v) postula orden y medida en la estructuración de lo real (tal como lo sostuviera Heráclito); todo esto con el propósito de «competir intelectualmente con las propuestas filosóficas de la época» ${ }^{7}$. La similitud de vocabulario habría hecho que Aristófanes homologue las figuras de Diógenes y Sócrates, sin haber comprendido, empero, según Sarri, la verdadera novedad intelectual que estaba introduciendo este último ${ }^{8}$. Si bien el estudioso italiano limita su observación a la concep-

${ }^{3}$ Cfr. Ar. Nu., v. 253.

${ }^{4}$ En cuanto al debatido problema de la historicidad del Sócrates de Aristófanes, en particular, y la del Sócrates de Platón y Jenofonte, en general, cfr. Souto Delibes, 1999, Gil, 2000-2002, y especialmente Cavallero, 2007-2008, que compendia 96 años de debate optando por profundizar la tesis de la autenticidad histórica del Sócrates de Aristófanes en base a la coincidencia de las fuentes. El presente trabajo se apoya sobre esa tesis.

${ }^{5}$ La parodia en Aristófanes no sólo es usada para burlarse de una obra o acontecimiento sino que, a su vez, cumple una precisa función cívica al estimular el pensamiento crítico del público «para modificar y mejorar conductas humanas a través de una situación cómica» (cfr. Frenkel, 2002: 240).

${ }^{6}$ Cfr. Bernabé, 1988: 273.

${ }^{7}$ Cfr. Bernabé, ibid.

${ }^{8}$ Cfr. Sarri, 1973: 546. 
ción del alma, retomando su argumentación se puede aquí sostener lo mismo pero con respecto a la práctica de la respiración y su vinculación con la actividad meditativa.

En efecto, el aér está estrechamente vinculado a la respiración y a la intelección en el sistema de Diógenes, según los fragmentos y testimonios que de él han sido trasmitidos:

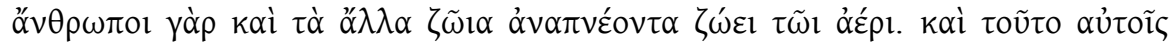

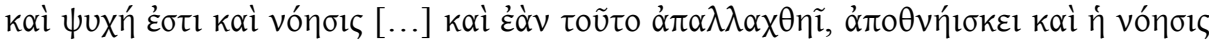
$\varepsilon \dot{\pi} \imath \iota_{\varepsilon i ́} \varepsilon \imath^{9}$.

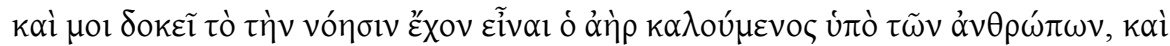

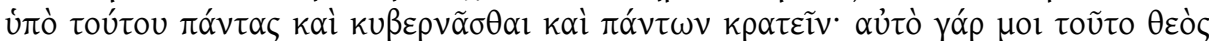

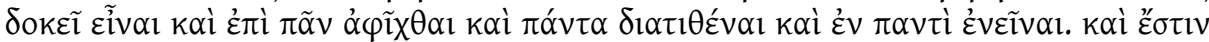

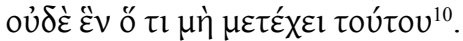

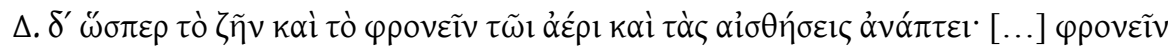

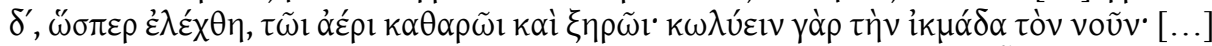

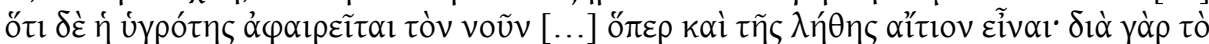

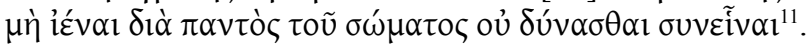

En este punto, es posible encontrar algún tipo de similitud entre la práctica espiritual de Sócrates y la teoría de Diógenes, en el supuesto de que Sócrates era heredero de una práctica que se remontaba a mucho tiempo antes que él ${ }^{12}$. El Aér , era concebido por Anaxímenes y, por el hecho de retomar su doctrina, también por Diógenes, no sólo como una sustancia o substrato material de orden puramente físico e hylético, sino también, en la misma medida, como un elemento fisiológico vinculado con la sensación y la percepción ${ }^{13}$ :

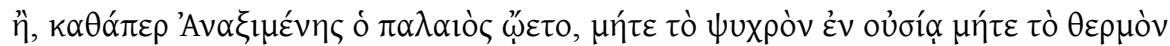

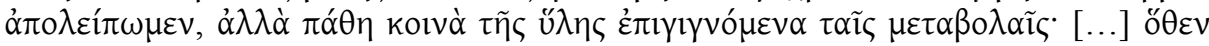

${ }^{9}$ Cfr. Diels-Kranz, fr. B 4: «los hombres, en efecto, y los demás animales, como respiran, viven gracias al aire, y éste constituye para ellos alma y entendimiento [...] Así que si se ven privados de él, mueren y el entendimiento les falta» (trad. esp. A. Bernabé).

${ }^{10} \mathrm{Cfr}$. Diels-Kranz, fr. B 5: «Así que me parece que lo que trae consigo el entendimiento es lo que los hombres llaman aire; por él se ven todos gobernados y dominan todas las cosas. Eso, en efecto, me parece que es la divinidad y que a todo alcanza, todo lo dispone y en todo reside. Ni una sola cosa hay que no participe de él» (trad. esp. A. Bernabé).

${ }^{11}$ Cfr. Diels-Kranz, A 19 (Teofrasto, Acerca de las sensaciones, 39): «Diógenes, de igual modo que la vida y el pensamiento, relaciona asimismo las sensaciones con el aire. [...] El pensar, como se dijo, se debe a aire puro y seco, ya que la humedad embota el entendimiento. [...] La humedad incluso priva del entendimiento. [...] Esa misma es la causa del olvido; como el aire no puede extenderse por todo el cuerpo, uno no puede comprender» (trad. esp. A. Bernabé).

${ }^{12}$ Cfr. Foucault, 2006: 45-6, 58-62.

${ }^{13}$ Respecto a esta diferencia, expresa A. Bernabé que «es menester precisar, sin embargo, que el término griego aér en los textos griegos más antiguos no se correspondía con exactitud a nuestro "aire". Cabría decir que concebían al aér más bien como niebla o vapor o, en todo caso, como aire perceptible en cuanto que se movía o se sentía caliente o frío» (A. Bernabé, 1988: 60). 


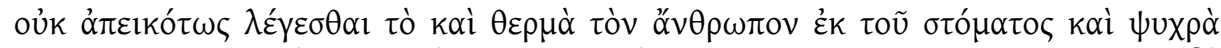

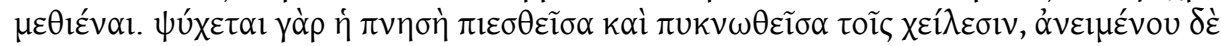

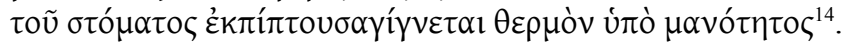

De aquí se puede conjeturar que la práctica y la importancia de la respiración ya estaba implícita en la actividad filosófica originaria aun cuando no era explícitamente expresada, y esta práctica quizá haya sido silenciada por ser parte de los misterios propios de la iniciación filosófico-espiritual. Según los testimonios de Aristófanes y Platón, Sócrates mismo usaba la terminología de los misterios de iniciación para hablar de la actividad filosófica ${ }^{15}$.

III. El pasaje 29c4 / 30b2 de Apología parece indicar en qué consiste específicamente el modo de vida de Sócrates, en tanto curador (epimeletés $s^{16}$ ) y meditador $\left(\text { phrontisté } s^{17}\right)^{18}$. El contexto es el de la recomendación del cuidado del alma (epimeleîsthai tếs psykhếs) y del meditar (phrontízein). Sócrates, hipotetizando sobre su

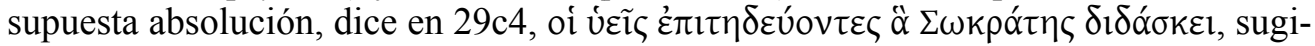
riendo que podría hablar acerca de aquellos de entre quienes lo escucharon que po-

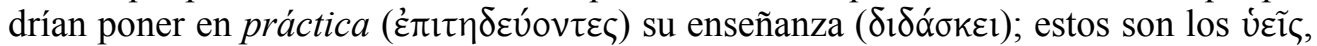

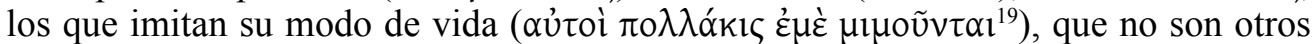

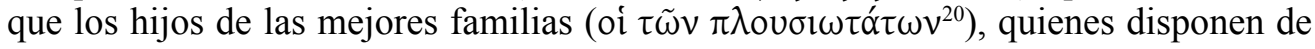

${ }^{14}$ Cfr. Plutarco, De primo frigido, 947f-948a: «O como pensaba el antiguo Anaxímenes no admitamos en la sustancia lo frío o lo caliente sino que afecciones comunes de la materia que sobrevienen en las transformaciones... [...] Que por eso se dice con razón que el hombre lanza desde su boca calor y frío. En efecto, el soplo, apretado y condensado por los labios, se enfría; en cambio, cuando sale de la boca abierta, es cálido a causa de la relajación» (trad. esp. R. Cornavaca).

${ }^{15}$ Cfr. Adkins, 1970: 18-24.

${ }^{16} \dot{\varepsilon} \pi \iota \mu \varepsilon \lambda \eta \tau n ́$ s significa «el que se ocupa de», de ahí «curador», «encargado», «vigilante», «administrador». El término puede representar un título oficial de director: i) en asuntos sagrados; ii) en asuntos

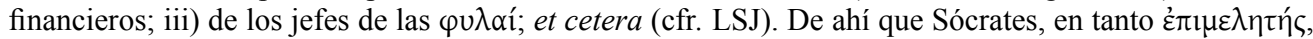
pueda ser considerado como ministro del dios (cfr. Pl. Ap., 31d; X. Ap., 12). Desde el punto de vista morfológico, se trata de un sustantivo con sufijo - $\tau\rceil \varsigma$ de agente (de profesión o de función [cfr. Lukinovich / Rousset § 189]). Sintácticamente, es complementado por un genitivo partitivo cūrae con los mismos

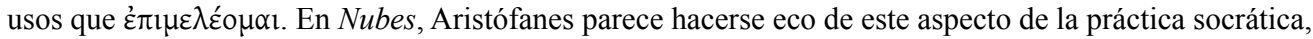
pues Strepsiádes al menos vislumbra que un buen aprendiz ( $\varepsilon \dot{u} \mu \alpha \theta \eta ́ \varsigma)$ de la doctrina que profesa Sócrates,

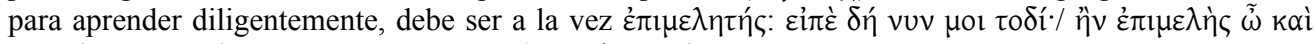

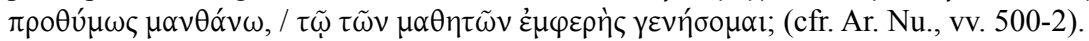

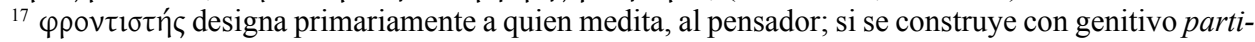
tivo cūrae toma la acepción de «quien toma cuidado de ( $\tau \iota v \tilde{\omega} v) »$. Puede significar, en comedia, «pensador profundo» («deep thinker, as Socrates is called in derision by Ar. Nu. 266; 414» [LSJ]) o «quien medita sobre los asuntos supra-terrestres», en la prosa histórica o filosófica (cfr. X. Smp. 6.6; Mem, 4.7.6; P1. Ap. 18b) y de ahí, filósofo en general. Puede presentar también el significado de «director» de una institución o actividad. Morfológicamente es un sustantivo deverbativo con sufijo - $\tau \eta \varsigma$ de agente, ex $\varphi \rho \circ \tau^{\prime} i \zeta \omega$.

${ }^{18}$ Afirma Hadot que «la figura mítica de Sócrates equivale a la figura misma del filósofo, la de aquél que "se ejercita" en la sabiduría» (cfr. Hadot, 2006: 18).

${ }^{19}$ Cfr. Pl. Ap., $23 \mathrm{c} 5$.

${ }^{20}$ Cfr. Ibid., 23c3. 


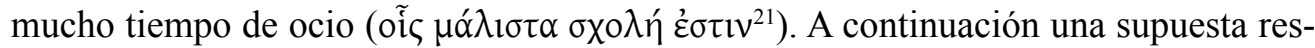

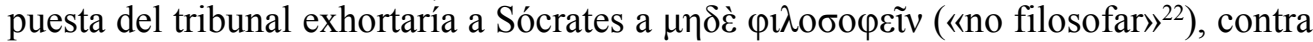
lo cual éste respondería algo que resultará ser una descripción de la caracterización del tipo de experiencia que se esconde detrás del ejercicio espiritual instanciado en el epimeleîsthai tệs psykhệs, verdadero horizonte del pasaje entero:

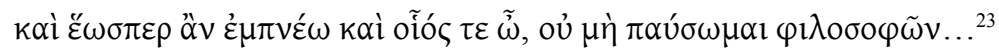

El ejercicio al que alude Sócrates primariamente consiste en empneîn («respirar», con preverbio $\mathfrak{e} v$ indica la idea de «respirar hacia el interior» y de ahí que signifique con mayor precisión «inhalar»), ejercicio preparativo básico (técnica ante todo fisiológica pero con efectos psico-somáticos asociada con el concepto primario de psykhé [«aliento vital», «soplo»]), que se practicaba desde antiguo como forma madre de todos los ejercicios espirituales ${ }^{24}$; siguiendo este ejercicio individual ${ }^{25}$ es que pue-

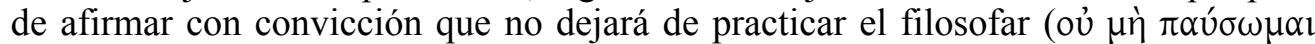
$\varphi \imath \lambda \circ \sigma o \varphi \tilde{\omega} v)$. pnéo tiene el sentido primario de «soplar»y de ahí «respirar». Cabe remarcar que esta acción está en la razón de ser de todo exercitium spirituale, en tanto ejercicio que, ante todo, se hace con el spiritus (cuyo sentido primario es «respiración» [ex spīro]), noción expresada en griego con un derivado de pnéó: pneûma ${ }^{26}$. Así, un ejercicio espiritual es fundamental y primariamente un ejercicio respiratorio, una

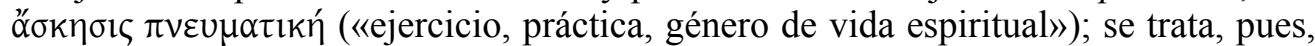
de la condición de posibilidad de todo exercitium spirituale ${ }^{27}$.

${ }^{21}$ Cfr. Ibid.

${ }^{22}$ Cfr. ibid., 29c 8.

${ }^{23}$ Cfr. ibid., 29d4-d5: «y mientras inhalare y fuere capaz, no voy a cesar de filosofar...» (la traducción es mía).

${ }^{24}$ Sobre la posibilidad de existencia de técnicas de control de la respiración entre los filósofos de la phýsis y en Grecia arcaica, cfr. Hadot, 1998: 198-199, quien menciona someramente el sentido que podría haber tenido la palabra $\pi \rho \alpha \pi i ́ \delta \varepsilon \varsigma$ en Empédocles. El término $\pi \rho \alpha \pi i ́ \varsigma$, usado en singular, es raro, generalmente se usa en plural, $\pi \rho \alpha \pi i ́ \delta \varepsilon \zeta$, significando «diafragma», cfr. $\Lambda, 579, \tilde{\eta} \pi \alpha \rho$ úrò $\pi \rho \alpha \pi i ́ \delta \omega v$; es

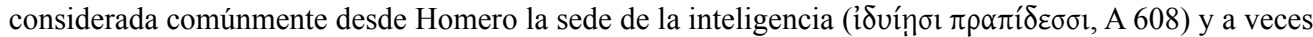
del deseo (cfr. $\Omega$ 514) [cfr. Chantraine]. Se trata de una palabra rara sin derivados ni compuestos, que puede equivaler, según Chantraine, a $\varphi \rho \varepsilon ́ v \varepsilon \varsigma$.

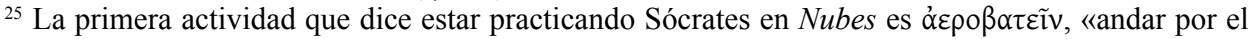

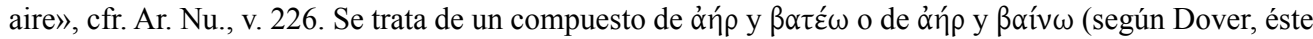

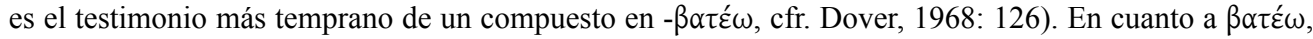
Bailly (y LSJ) lo refiere a $\pi \alpha \tau \varepsilon ́ \omega$, «caminar», «avanzar», o al adjetivo verbal de posibilidad de $\beta \alpha i ́ v \omega$,

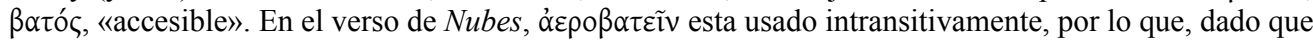
$\beta \alpha i ́ v \omega$, en dicha función, significa «andar», «ir(se)», «salir(se)» (cfr. Bailly), Sócrates estaría «ido» en el aire, absorto en la práctica de un ejercicio de respiración, cfr. infra IV, V, VI.

${ }^{26}$ Según LSJ, el término $\pi v \varepsilon \tilde{v} \mu \alpha$, a lo largo de su historia, presentó las siguientes acepciones: i)

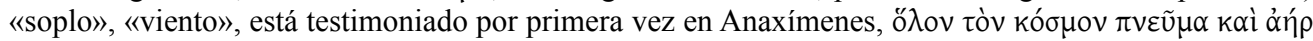
$\pi \varepsilon \rho i ́ \varepsilon \chi \varepsilon l$ (cfr. fr. 2 Diels-Kranz [nótese que ya aparecían en conjunción ơń $\rho$ y $\pi v \varepsilon \tilde{v} \mu \alpha]$ ); ii) aire de la respiración, respiración; iii) inspiración divina; iv) el espíritu de Dios, $\pi v \varepsilon \tilde{v} \mu \alpha$ $\theta \varepsilon \circ \tilde{v}(\mathrm{NT})$; v) espíritu del hombre (NT); vi) ser espiritual o inmaterial, ángel (NT).

${ }^{27}$ Pierre Hadot es quien, en la actualidad, le ha dedicado gran atención a la noción de ejercicio espiritual. Un exercitium spirituale es, ante todo, una práctica $(\pi \rho \tilde{\alpha} \xi ı)$ respiratoria (que presenta vínculos 
Sócrates, entonces, afirma con seguridad que mientras ejercite la respiración y sea capaz, no va a dejar de practicar la filosofía. Hay que considerar el valor semántico del subordinante temporal $\tilde{\varepsilon} \omega \varsigma$, que puede indicar: i) una temporalidad de simultaneidad absoluta e indeterminada, «mientras que», o ii) una temporalidad con valor télico y determinada, «hasta que» ${ }^{28}$. A su vez, la frase forma un período temporal eventual, dónde la prótasis es eventual (ốv cum subjuntivo) y la apódosis real con valor de futuridad. La particula $-\pi \varepsilon \rho$, por su parte, le da un valor de precisión, seguridad y énfasis a lo afirmado en la prótasis por el hablante. Así pues, o bien Sócrates afirma que mientras sea capaz de practicar el ejercicio de respiración, a la vez no dejará de practicar el filosofar, o bien que filosofará hasta el momento que ya no sea capaz a la vez de practicar el ejercicio espiritual. De cualquier manera, la acción de practicar la respiración es en ambos casos

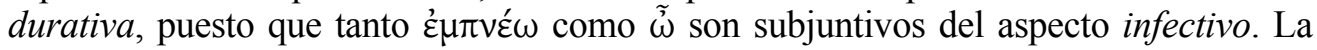
eventualidad, entonces, está puesta en respirar y poder hacerlo, dado que, aun cuando no sabe con certeza si seguirá filosofando o no, o si será capaz de hacerlo, sí tiene la seguridad de que, si cumple esa condición, es necesario que lo haya de practicar. De aquí que también pueda tener un valor de universalidad el subjuntivo con la partícula ớv, en el caso de que se la considere según $i$, i. e., siempre que Sócrates practique el ejercicio de respiración y tenga la capacidad de hacerlo, necesariamente habrá de practicar, simultá-

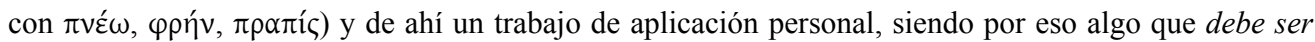
vivenciado por uno mismo. Más que contenidos, le da forma al alma. El predicado «espiritual» le cabe con mayor pertinencia que «intelectual», «físico», «ético», «del pensamiento», o «del alma», pues «estos son producto no sólo del pensamiento, sino de una totalidad psíquica del individuo» (cfr. Hadot, 2006: 24). Se trata pues, de una práctica más vasta porque incluye en su experimentación a las restantes partes de la $\psi v x \eta ́$, es decir, la sensitiva, la imaginativa, la intelectiva, la volitiva y pone en juego la totalidad de sus capacidades. Consiste así, en una verdadera $\psi v x \alpha \gamma \omega \gamma$ í $\alpha$. Spirituale, entonces, predicado de exercitium señala la cristalización, en una homogeneidad holística, de todos los aspectos de la $\psi v x \eta ́$ que el calificativo engloba y dirigir la atención sólo a alguno de ellos es considerarlo desde «un punto de vista demasiado limitado» (cfr. ibíd.). De la enumeración que realiza el mismo Hadot (2006) a partir del listado de Filón de Alejandría, se puede hacer una clasificación de los distintos exercitia spiritualia en: (a) de inspiración es-

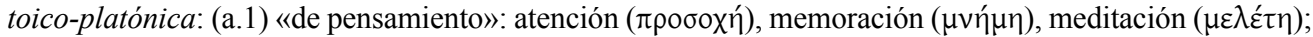

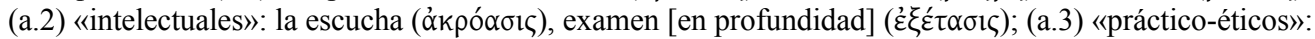

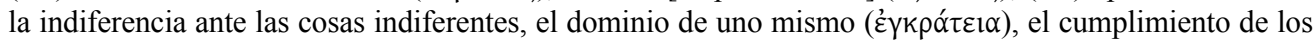
deberes; (b) de inspiración epicúrea: la terapia de las pasiones; (c) de inspiración escéptica: equivalencia

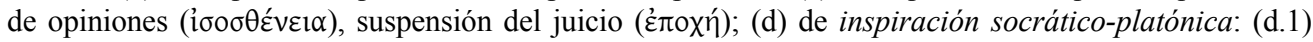

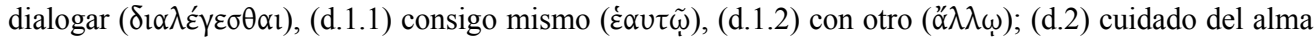
$\left(\dot{\varepsilon} \pi \iota \mu \varepsilon \lambda \varepsilon \tilde{\varepsilon} \sigma \theta \alpha \iota \tau \tilde{\eta} \varsigma \psi \cup \times \tilde{\eta} \varsigma\right.$, contenido subrepticiamente en una de las máximas del oráculo délfico: $\Gamma \nu \tilde{\omega} \theta_{1}$

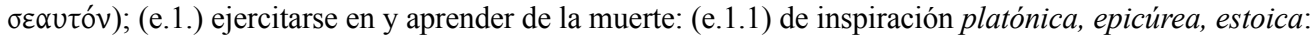

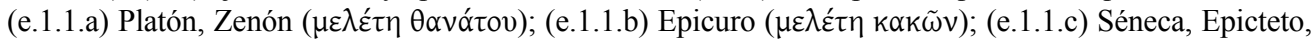
Marco Aurelio (praemeditatio malōrum); (e.1.a) ejercitarse en y aprender de la muerte: contemplación de la naturaleza (Aristóteles, Diógenes, Lucrecio, Epicteto, Marco Aurelio, Filón); (e.1.b) ejercitarse en y aprender de la muerte (progreso espiritual): (e.1.b.1) alejar el pensamiento de todo cuanto es carnal y mortal (= cuerpo); (e.1.b.2) entregarse a la actividad del Noṽ (Plotino, Porfirio) [cfr. ibid.: 27-48 / 257]. Todos estos ejercicios espirituales antiguos serán reactualizados y refuncionalizados por la tradición cristiana hasta ser compendiados por Ignacio de Loyola en sus Exercitia Spiritualia [cfr. ibid.: 24-25].

${ }^{28}$ La significación de $\tilde{\varepsilon} \omega \varsigma$, a diferencia del subordinante $\dot{\varepsilon} \vee \omega ّ$ que representa con precisión la simultaneidad indeterminada total, «mientras que», o de $\mu$ źxpı oú que expresa exactamente la simultaneidad determinada, «hasta que», presenta la ambivalencia de sentido resoluble en función del contexto enunciativo; cfr. Humbert, $\S 281, \S 346$. 
neamente y de manera continuada, la actividad filosófica, que es una práctica subordinada al epimeleîsthai tês psykhế $s^{29}$ y al phrontízein ${ }^{30}$, estando estas, asimismo, subordinadas al empneîn. La secuencia que ilustra la práctica del ejercicio espiritual socrático en su totalidad sería: a) técnica de control y concentración de la respiración, empneîn, b) cuidado del alma, epimeleîsthai tếs psykhêes, c) meditación, phrontízein, y d) filosofar, philosopheîn (en el sentido de practicar, principalmente, la dialéctica, dialégesthai $\left.{ }^{31}\right)^{32}$.

\section{La primera invocación de Sócrates al Aér en Nubes tiene la siguiente forma:}

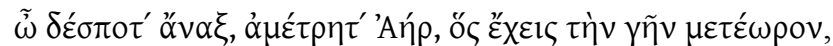

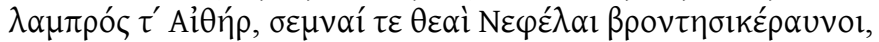

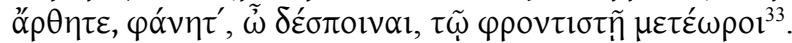

${ }^{29}$ En rigor la formulación completa de esta fase del ejercicio espiritual es, parafraseando la formula-

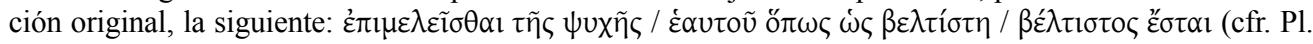
Ap., 29e $2 ; 30$ b 1-2; 36c 6-7). Hay que notar que el verbo, en tanto verbum cūrandi, es complementado por: i) un genitivo partitivo cūrae, que designa un objeto que se considera con penetrante atención en detrimento de la totalidad de la que es extraído (cfr. Humbert, § 453), indica, así, el partitivo, un objeto de concentración en un sentido psicológico-perceptivo; ii) el subordinante ö $\pi \omega \varsigma$ indica el propósito del cuidado y revela la intención volitiva del sujeto; iia) dentro de la proposición sustantiva subordinada introducida por ö $\pi \omega \varsigma$, aparece un $\dot{\omega} \varsigma$ intensivo con superlativo, lo que hace recaer el énfasis en el propósito mismo del cuidado (Havelock afirma que «the emphasis of the phraseology is not moral but functional» [cfr. Havelock, 1972: 5]), y el verbo en futuro que le da una idea de orientación hacia un objetivo (cfr. Humbert, § 384) . A partir de Sócrates el termino $\psi \cup x \eta ́$, es el complemento habitual que acompaña a este verbum cūrandi y

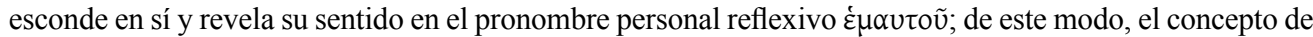
$\psi v x \eta ́$ deja sus anteriores significados para comenzar a identificarse con la propia interioridad del meditador, con la noción de «uno mismo» (cfr. Havelock, 1972: 3-9). Para las nociones contenidas en el concepto de $\psi u x \eta ́$ antes de Sócrates, se puede consultar, Burnet, 1990: 28-45, Sarri, 1973: 534-542, Havelock, 1972: 5; para el sentido que comienza a tener a partir de Sócrates, se puede ver, Burnet, ibid.: 45-9, Sarri, ibid.: 542-546, Havelock, ibid.: passim, Reale, 1998, cap. 12, y especialmente Foucault, 2006: 65-71.

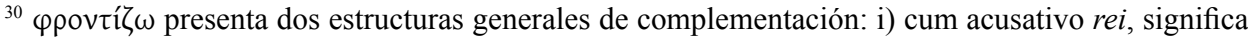

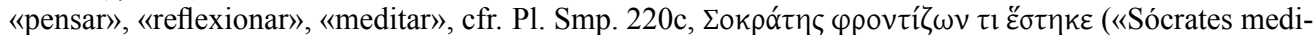
tando / reflexionando algo se quedó de pie»); ii) cum genitivo partitivo cūrae, toma el valor de «inquietarse por», «(pre)ocuparse en»; «cuidar de». En cuanto a su morfología, es un verbo denominativo con

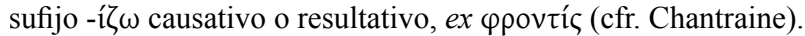

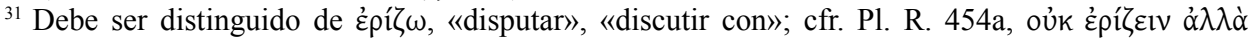

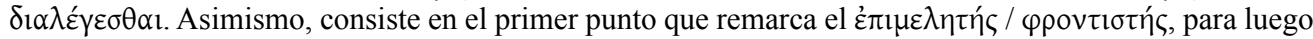

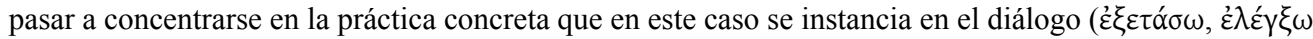
[cfr. Pl. Ap. 29e5]) con otro.

${ }^{32}$ El texto continúa y también los participios dependientes de $\pi \alpha u ́ \omega, \pi \alpha \rho \alpha \kappa \varepsilon \lambda \varepsilon v o ́ \mu \varepsilon v o \varsigma$ y $\varepsilon$ $v \delta \varepsilon 1 \kappa v u ́ \mu \varepsilon v o \varsigma$, por lo que habría un momento posterior, $e$, de carácter cívico o "social», pues Sócrates también afirma que no cesará de reconvenir o dar indicaciones a sus conciudadanos; se trata del paso del

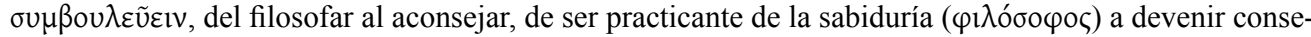
jero o director de consciencia ( $\sigma \cup \mu \beta$ dado de sí hacia el cuidado de otros. Para la figura de Sócrates como consejero o director de consciencia, cfr. Des Places (1938), quien intenta demostrar que este aspecto de Sócrates, testimoniado por Platón, se encuentra también aludido en Nubes por Aristófanes.

${ }^{33}$ Cfr. Ar. Nu., vv. 264-6: «iOh amo soberano, inconmensurable Aire, que mantienes la tierra suspendida, / y brillante Éter, y venerables diosas, Nubes truenorelampagueantes, / elévense, aparézcanse, oh amas, para el meditador suspendidas!» (la traducción es mía). 
En la invocación hay tres entidades invocadas, de entre las cuales, el Aér ocupa curiosamente el primer lugar ${ }^{34}$. Al final de la invocación, llamativamente, se repite el mismo adjetivo con que finaliza el primer verso, $\mu \varepsilon \tau \varepsilon \dot{\varepsilon} \omega \rho \varsigma^{35}$, pero con la diferencia de que es complementado por una palabra que no es para nada inocente en esta comedia ${ }^{36}$ y que está muy estrechamente vinculada, en cuanto a su etimología, con el campo se-

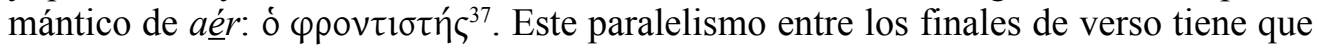
llamar la atención: en el v. 264 aparece dentro de una proposición relativa adjetiva cuyo antecedente es $A \underline{e} r$; en el v. 266, si bien referido a las Nubes, está curiosamente complementado por $\tau \tilde{\omega} \varphi \varphi \rho o v \tau \imath \sigma \tau \tilde{n}$. Se podría pensar en intercambiar las estructuras

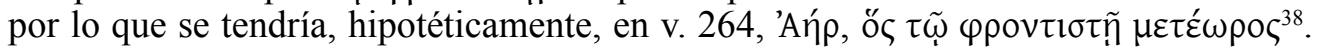
Esta hipótesis haría suponer una proximidad entre el Aér y la phrontis ${ }^{39}$ :

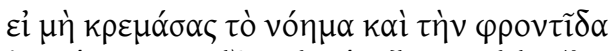

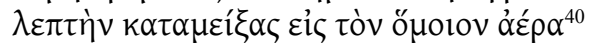

${ }^{34} \mathrm{Si}$, como ha sido dicho más arriba, Aristófanes está parodiando las explicaciones cosmológicas de los physicoí, no resulta llamativo el orden de la invocación, pues 'Ań $\rho$ significaba todavía para estos, conforme con la creencia tradicional, la parte más baja de la atmósfera (cfr. $\Xi, v .228$ ) mientras que Aïń $\rho$ la parte más alta (cfr. P, v. 425).

${ }^{35} \mu \varepsilon \tau \varepsilon \dot{\varepsilon} \omega \rho \circ \varsigma$ significa «elevado», «suspendido (en el aire)»y también presenta el sentido de «quien yergue o levanta la cabeza (en señal de arrogancia)», cfr. Bailly.

${ }^{36}$ Cfr. nota 53.

${ }^{37}$ Cfr. nota 39.

${ }^{38}$ Nótese que, desde el punto de vista métrico, dicho intercambio no lesionaría la métrica: efectivamente, en v. 264 el esquema métrico es $-\cdots$, siendo idéntico el cuarto metro e intercambiable el tercero de v. 264 con los respectivos de v. 266. Dado que el esquema métrico en esta parte de Nubes es el tetrámetro yámbico cataléctico, el yambo del quinto pie de v. 264 puede ser equivalente al espondeo del quinto pie de v. 266; cfr. Koster, 1953.

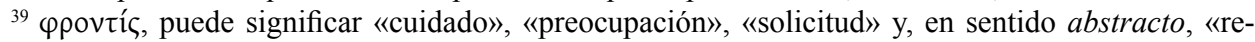
flexión», «meditación»e incluso «sentimiento». El término es especialmente aplicado a las especulaciones de Sócrates y los filósofos (cfr. LSJ). De acuerdo a su acepción abstracta, habría que traducir

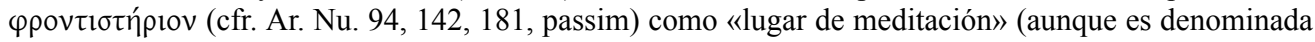

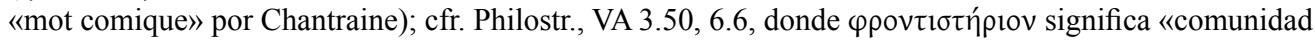

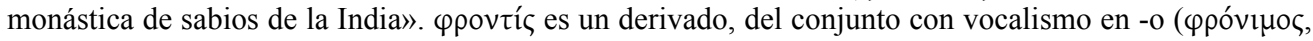

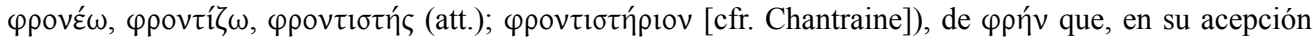
más general, designa toda membrana que recubre un órgano (cfr. Bailly) y más vagamente, «entrañas». De ahí que pueda significar: i) «corazón», en tanto sede de las pasiones; ii) «espíritu», en tanto sede del pensamiento; iii) «voluntad» (cfr. Chantraine). En tanto término del ámbito anatómico, no hay unanimidad entre los estudiosos para determinar su significado, pudiendo querer decir: a) «diafragma» (Snell), b) «pericardio» (Körner), c) «pulmones» o «un grupo de órganos en la parte superior del cuerpo» (Onians). A partir de los adjetivos en - $\varphi \rho \omega v$, Lockhart [1966: 99-101] intenta derivar un sentido antiguo de «respirar» en Homero en concordancia con la propuesta de Onians. Podría estar relacionado, a su vez, con vóoৎ o Өujós (cfr. Magnien, REG 40, 1927: 117-141).

${ }^{40}$ Cfr. Ar. Nu., vv. 230-1: «si no al suspender lo aprehendido y la reflexión, / desollada, al mezclar(la hacia abajo) con el similar aire» (la traducción es mía). 
La clave del pasaje está en el adjetivo que determina a aér, ö $\mu$ oı completar su sentido propio, «semejante a», exige un régimen ${ }^{41}$. Sabido es que los términos cuyo componente léxico connota la idea de semejanza o similitud son complementados por un dativo similitüdinis ${ }^{42}$; aquí hay que recordar el dativo de v. 266,

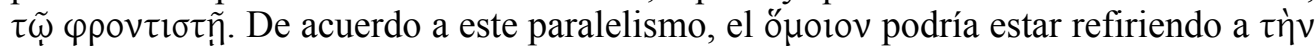
$\varphi \rho \circ \vee \tau \tilde{\imath} \delta \alpha$ del verso anterior. Nótese la siguiente sutil diferencia: mientras ǒ $\mu$ orov está

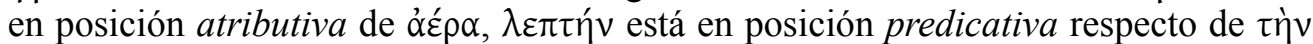
$\varphi \rho \circ \vee \tau \tilde{\imath} \delta \alpha$. Un atributo denota una cualidad o propiedad permanente de una entidad, en cambio un predicativo una propiedad o característica accidental de una entidad. ¿Cómo habría que interpretar este detalle? Se podría suponer que se trata de una mera disposición de palabras por razones métricas. Pero una mirada más atenta rechaza por simplista esta hipótesis. El orden podría sugerir otra relación entre las palabras y sus significados. El aér posee la característica permanente de ser similar a la phrontís siempre que esta devenga sutil, ligera, siempre que se acerque a la cualidad esencial del aér que es, en sí mismo, un elemento delicado, siendo el condicional inverso falso. Así pues, hay que suponer que los términos están trastocados: hómoios sería la phrontís siempre que se adapte al leptós ${ }^{43}$ aér , y no a la inversa. Fíjese la atención

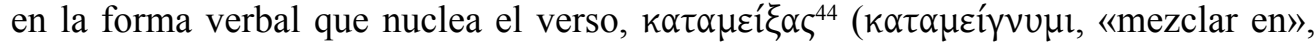
«combinar»): el verbo podría sugerir, mediante el preverbio kató, la idea de que el aér y la phrontís se mezclan bajando hacia y son retenidos en el diafragma, por lo que está técnica respiratoria, concentrada en el phréen ${ }^{45}$, engendra una phrontís refinada, lepté. El aér es hómoios a todo lo leptós; la phrontís, en la medida en que se adapta a lo leptós, tiene semejanza con el aér y, sólo entonces, se pueden combinar en una

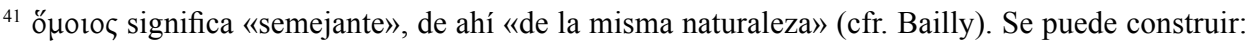
i) cum dativo similitūdinis, «que se adapta a», «igual a», «del mismo valor que» (cfr. LSJ; Bailly); ii) cum acusativo de relación, "semejante en cuanto a». Iguala en status los elementos puestos en relación. La base ó $\mathrm{o}_{\mathrm{o}}$ contiene la idea de «mismidad» (cfr. Chantraine).

${ }^{42}$ El dativo de semejanza o asociación indica una relación de coexistencia o comunidad (cfr. Berenger Amenós, § 296) entre dos entidades concretas o abstractas. El componente léxico connota una idea de asociación independientemente de la relación sujeto-objeto (cfr. Lukinovich / Rousset, § 264), porque el dativo, en su valor de caso concreto (cfr. Humbert, $\S 406,472$ ), puede denotar una función $(F x)$ biyectiva sujeto-sujeto / objeto-objeto (cfr. Lukinovich / Rousset, § 260; Humbert, § 482; Schwyzer / Debrunner, B I.4f. III.1). Puede connotar, asimismo, una idea de comparación, siempre que el componente léxico implique una idea de semejanza o identidad (cfr. Lukinovich / Rousset, § 63). Sin entrar en esta compleja cuestión, sin embargo se puede señalar que el genitivo, en su faceta de caso puro, expresa una relación sujeto-objeto, ya sin estar implicada la acción (genitivo adnominal), ya estando implicada (genitivo partitivo); el acusativo, a su vez, es el caso por excelencia de la transitividad y, por esto, de la necesaria relación sujeto-objeto mediada por la acción verbal.

${ }^{43}$ El adjetivo $\lambda \varepsilon \pi \tau$ tó, ท́, óv quiere decir «sutil», «ligero», «refinado».

${ }^{44} \mathrm{El}$ aoristo estaría marcando una actividad puntal y no habitual, el momento preciso de los dificultosos cambios de fase dentro del ejercicio espiritual. Rogers en su edición adopta la lección $\kappa \alpha \tau \alpha \mu i ́\} \alpha \varsigma$, la formación con el radical puro $\mu \mathrm{r} \gamma-$, presente en el tema de confectivo, y por tanto más arcaica que la innovación con vocalismo en $e, \mu \varepsilon ı \gamma$, presente en el tema de infectivo, $\mu \varepsilon i ́ \gamma v u \mu$, y luego extendida, como característica regular, a toda la conjugación, cfr. Chantraine. Adoptada esta lección, podría reforzar la hipótesis de un uso del término en contextos filosóficos más antiguos donde se habría ejercitado la espiritualidad, como el pitagorismo o el orfismo.

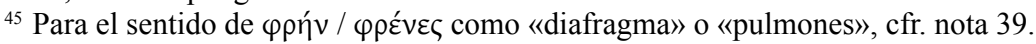


unidad; y ya siendo de la misma naturaleza son concentrados y retenidos en el diafrag$\mathrm{ma}^{46}$. El nóe $\mathrm{ma}^{47}$, sin embargo, en tanto producto de la actividad aperceptiva, queda suspendido ( $\left.\kappa \rho \varepsilon \mu \alpha ́ \alpha \sigma \varsigma^{48}\right)$, por lo que la práctica de la espiritualidad deja de lado, durante un cierto tiempo, los aspectos del ejercicio espiritual que puedan tener un matiz puramente noético, para purificar la phrontís. Además, leptós es, morfológicamente, un adjetivo verbal de posibilidad (que también puede equivaler semánticamente a un participio medio-pasivo de perfectivo ${ }^{49}$ ) de lépo ( «pelar», «desollar»; tiene un sentido concreto «sacar la corteza [a un árbol]; descascarar [un fruto]). Así, la phrontís, al devenir leptós, es lo que queda como núcleo del nóema y, por extensión, de la actividad meditativa: alcanzado este status, se mezcla y tiene una relación de mismidad con el aér. De este modo, la phrontis lepté supone una actividad puramente espiritual que, como tal, es condición necesaria de la transformación del individuo en tanto epimelétés / phrontistés, al ser la que le abre la posibilidad de alétheia ${ }^{50}$.

V. Hasta aquí se ha visto que con el empneîn comienza el ejercicio espiritual socrático y su desarrollo meditativo instanciado tanto en el epimeleîsthai tếs psykhếs / emautố como en el phrontízein que, en los versos de Nubes precedentemente estudiados, aparece descripto con algún detalle en relación con la utilidad del aire y la técnica de control de la respiración. Los siguientes versos de Aristófanes podrían ilustrar el momento final del ejercicio respiratorio en relación con la actividad meditativa:

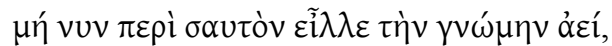

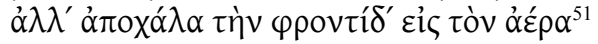

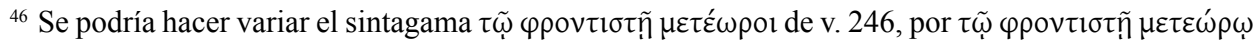
que, según la segunda acepción de $\mu \varepsilon \tau \varepsilon ́ \omega \rho o \zeta$ indicada en nota 35 , podría significar «al meditador erguido» con lo que se señalaría la postura corporal adecuada para que sea efectivo el ejercicio respiratorio, es decir, para que el aire llegue hasta y quede contenido en el diafragma.

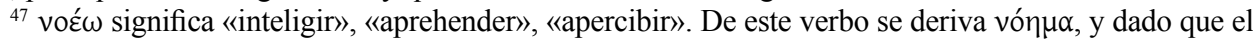
sufijo - $\mu \alpha$ designa el resultado de una acción o proceso (cfr. Lukinovich / Rousset, § 190), tiene que significar «lo que es aprehendido / inteligido / apercibido»; de ahí que en filosofía pueda ser entendido como «concepto» (cfr. LSJ), como «lo concebido» en oposición a lo sensible (cfr. Parm. fr. 7, vv. 2-5 [para un análisis de la significación de esta oposición en Parménides, cfr. Cordero, 2005: 149-154]). Dover con-

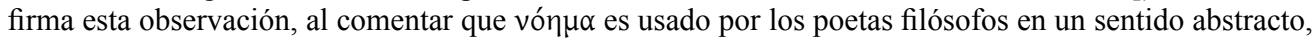
refiriendo a Jenófanes fr. 19.2 y Empédocles Pa. 105.3 (cfr. Dover, 1968: 127).

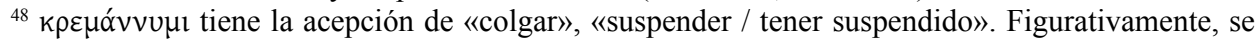
dice del espíritu, de la atención (cfr. Bailly). Un derivado es aplicado a Sócrates también en Nubes,

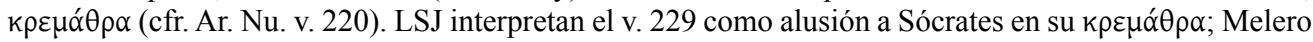
en clave pitagórica, como intentando Sócrates mantener separado el cuerpo del alma (cfr. Melero, 1971: 429); Giudorizzi ve una alusión a doctrinas arcaicas tardías de tipo mistérico-filosóficas, como las órficas (cfr. Giudorizzi, 2002: 222).

${ }^{49}$ Cfr. Smyth-Messing, § 472.

${ }^{50}$ M. Foucault establece que ya desde (y aún antes de) Sócrates, existía una diferencia entre filosofía y espiritualidad, en tanto transformación del «ser del sujeto» para acceder a la verdad; cfr. Foucault, 2006: 33-38.

${ }^{51}$ Cfr. Ar. Nu. vv. 762-3: «entonces, no embrolle siempre el conocimiento [tradicional / enseñado] alrededor de usted mismo / sino suelte la reflexión hacia el aire» (la traducción es mía). 
El consejo que el symbouleutés (Sócrates) está dando al mathêtés (Strepsiádes) con el imperativo de $\alpha \dot{\pi} \pi \circ \alpha \lambda \alpha$ á $\omega$ (que por ser del aspecto infectivo estaría sugiriendo que está explicando al mathêtés el procedimiento, sin estar este último practicándolo efectivamente) consiste en aflojar, en soltar el aire, en exhalar, en el supuesto de que está enseñando la práctica de un ejercicio espiritual, y representa el momento de relajar la tensión causada por el esfuerzo que supone la concentración y retención del aire ${ }^{52}$. En el apartado anterior quedó dicho que el aér y la phrontís, luego de asimilarse y tras dejar de lado, momentáneamente, al nóéma, forman una unidad que nuclea a todo el ejercicio espiritual. Esta operación de la psykhé supone al nóęma aunque parece ser indiferente, una vez alcanzada esta fase, al conocimiento tradicional, a la $\gamma v \omega ́ \mu \eta^{53}$. El preverbio ảmó podría estar indicando el lugar de donde habría que soltar el aire retenido ${ }^{54}$, i.e., el diafragma. Con esto estaría indicada aquí la parte final del ejercicio espiritual, la fase en donde el aire debe ser liberado para que pueda ser recomenzado desde el ejercicio respiratorio, cuya secuencia completa, ordenada, consistiría, según lo visto hasta aquí, en:

i) empneîn

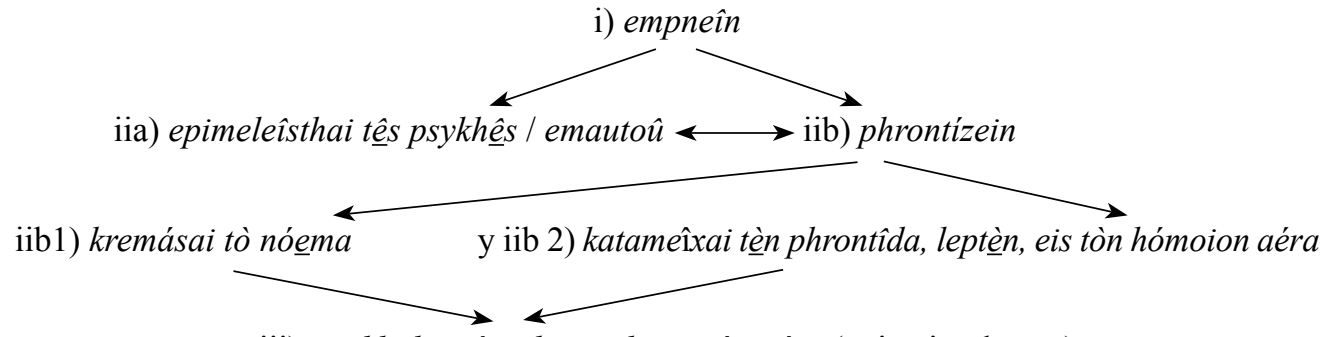

iii) apokhalân tèn phrontîda eis tòn aéra (et in circulum: $i$ )

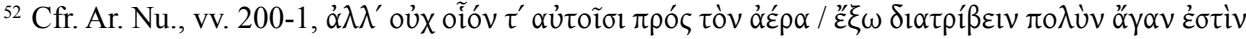

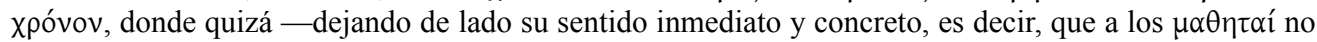

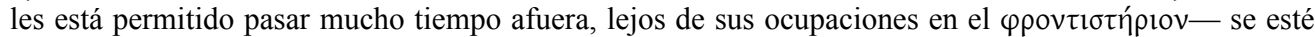
haciendo alusión a que los aprendices $(\alpha u ̉ \tau o i ̃ \sigma l=\mu \alpha \theta \eta \tau \alpha i ́)$ deben, más que sacar el aire, retenerlo y con-

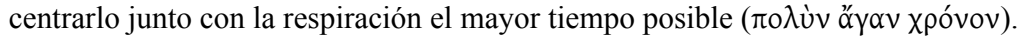

${ }^{53}$ La diferencia entre i) $\varphi \rho o v \tau i ́ c$, ii) vón $\mu \alpha$ y iii) $\gamma v \omega ́ \mu \eta$ en Nubes consiste en que, $i$ (y sus formas asociadas) es el término más frecuente que usa Sócrates y está siempre referido a la actividad intelectiva

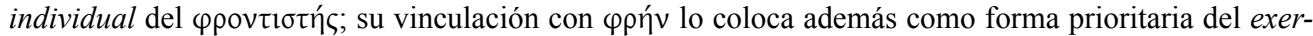
citium spirituale; representa, asimismo, la actividad propiamente meditativa; con iii se hace referencia a una relación de enseñanza entre maestro y discípulo y por tanto, el conocimiento que de ella resulta, está dentro de la práctica del $\mu \alpha v \theta \alpha ́ v \varepsilon ı v$ y del $\delta 1 \delta \alpha ́ \sigma k \varepsilon ı v ; i i$ es el que aparece con menor frecuencia, pero

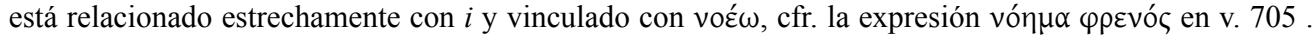
En las partes de la comedia en las que aparece Sócrates (vv. 224-275, 291-297, 314-517, 627-813, 868$888,1145-1169,1502-1504$ ) o que anticipan su aparición obrando sus mathetai (vv. 133-224), ocurren

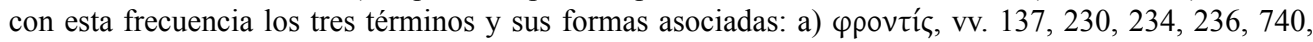

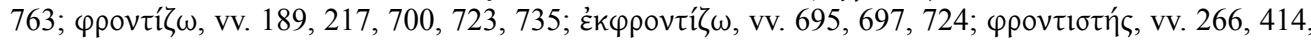

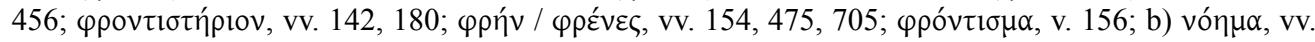

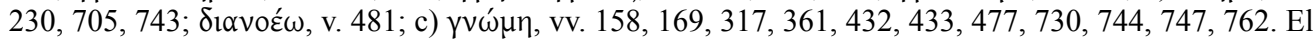
estudio de las relaciones diferenciales vó $\mu \alpha \neq \gamma \nu \omega ́ \mu \eta \neq \varphi \rho o v \tau i ́ c$ en Nubes, arrojaría aun más luz sobre la peculiar actividad filosófica de Sócrates en relación con la práctica de la espiritualidad.

${ }^{54}$ Igualmente, el preverbio úto de la forma útroxó $\lambda \alpha$ que trasmite el manuscrito N (cfr. Dover, 1968), podría sugerir que el aire está ubicado en la parte inferior del aparato respiratorio, el diafragma, y para ser exhalado debe subir hacia la boca y la nariz. 
VI. La segunda vez que Sócrates invoca al Aér en $N u b e s^{55}$, lo hace de acuerdo a esta otra curiosa expresión:

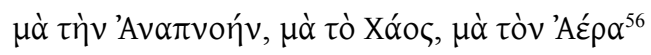

Lo que inmediatamente salta a la vista en esta invocación es la primera entidad invocada, la 'Avarvoń, la respiración ${ }^{57}$. En su campo semántico están incluidas ${ }^{58}$, conforme con su sentido general de «respiración», tanto la eispnoé, la inhalación, como la ekpnoé, la exhalación ${ }^{59}$. Aunque de acuerdo a su significación particular, anapnoé es equivalente a la eispnoé en tanto opuesta a la ekpno $\underline{e}^{60}$. No obstante, debido a la preposición $\alpha^{v} \alpha^{6}{ }^{61}$, se podría creer que el término en realidad supone la noción de ekpnoé antes que la de eispno $\underline{e}^{62}$, puesto que el aire inhalado baja $^{63}$ hacia la zona del diafragma mientras que el exhalado sube desde el. La mención y el lugar que ocupa hacen más que elocuente su aparición en esta invocación, pues Sócrates los invoca para expresar su indignación frente al carácter insuficiente y las características negativas de su aprendiz, de su mathêtés (ágroikos, áporos, skaiós, epilésmon $n^{64}$ ) sugiriendo que éste ni siquiera es capaz de poner en marcha el ejercicio espiritual desde el principio, es decir, comenzando con el ejercicio de respiración.

En cuanto a la mención del Xóos, los estudiosos han visto una referencia, junto con el Aithér, a la cosmogonía órfica ${ }^{65}$. A su vez, el sentido que tiene desde Hesíodo

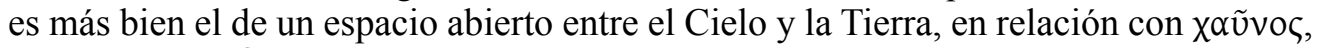
«vacío», y $\chi \alpha v \delta \alpha ́ v \omega, ~ « c o n t e n e r »{ }^{66}$. En cambio, de acuerdo a lo desarrollado en este

${ }^{55} \mathrm{Cfr}$. Ar. Nu. v. 667, donde hay una tercera invocación al Aér $r$ pero esta vez en boca de Strepsiádes

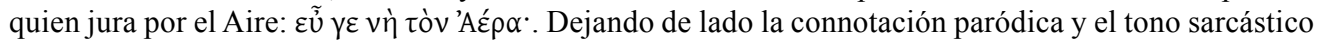
que pueda tener esta invocación en boca de este personaje de Nubes (cfr. Cavallero et alli, 2008: 221, nota 5), hay que considerar que Strepsiádes, precisamente, está en vía de iniciación y estaría tomando

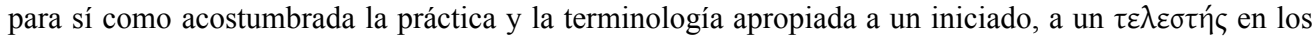
misterios de la actividad filosófica practicada por Sócrates.

${ }^{56}$ Cfr. Ar. Nu., v. 627: «iNo, por la Respiración, no, por el Caos, no, por el Aire!» (la traducción es mía).

${ }^{57} \dot{\alpha} v \alpha \pi v o \eta ́$ designa la «acción de extraer el hálito» y de ahí «respiración»; está relacionada con el verbo $\dot{\alpha} v \alpha \pi v \varepsilon \dot{\varepsilon} \omega$ (cfr. Bailly), «exhalar», «respirar».

${ }^{58}$ Cfr. LSJ.

${ }^{59}$ Cfr. Pi. P., 3.57; Pl. Ti., 33c.

60 Cfr. Arist. Resp., 471a 7, 480b 10; Pl. Ti., 78e, 79e.

${ }^{61}$ Antes de la definición que da Bailly de åva $\pi v o \eta ́$, pone una aclaración: «ảvó, en haut».

${ }^{62}$ Esto está más de acuerdo con lo dicho al respecto por Teofrasto, cfr. Thphr. H.P., 6.2.4.

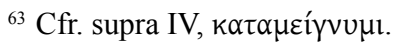

${ }^{64}$ Cfr. Ar. Nu., vv. 628-9.

${ }^{65}$ Cfr. Gelzer, 1956: 67; Sarri, 1973: 543.

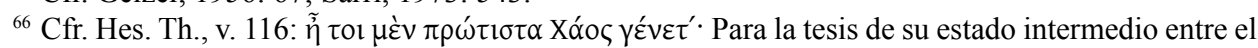
Cielo y la Tierra, cfr. Liñares, 2005: 38-9. Grimmal da la siguiente definición: «Caos es la personificación del Vacío primordial, anterior a la creación, cuando el Orden no había sido impuesto aún a los elementos del Mundo. Engendró el Érebo y la Noche, luego el Día y el Éter. A veces, por el contrario, se le presenta como hijo del Tiempo y hermano de Éter.», cfr. Grimmal, 2008: 85-6. Aristófanes lo había mencionado ya en v. 424 de Nubes y lo vuelve a hacer tres veces en la parábasis propiamente dicha de Aves (además de ser la otra comedia que hace mención a la «misteriosa» actividad filosófica de Sócrates, cfr. Av. vv. 
trabajo, se propone indicar que con Kháos se hace alusión a un punto cero, al vacío $a_{\text {bsoluto }}{ }^{67}$, a lo que está ontológicamente antes de cualquier entidad ${ }^{68}$. De este modo, el epimeletés / phrontistés, mediante su ejercicio espiritual, se remontaría y sumergiría en los fundamentos últimos y más profundos de su ser, hacia las profundidades de su psykhé / heautón.

Por la forma que tiene esta invocación de Nubes, el Kháos está enmarcado, por una estructura abrasiva, entre anapnoé y aér, por lo que habría que suponer que tendría un lugar central y decisivo como momento del ejercicio espiritual. Efectivamente, por etimología está vinculado con $\chi \alpha{ }^{\prime} v \omega^{69}$ : luego de la purificación de la phrontís, el epimelétés / phrontistés accedería a este estado de contemplación de la unidad primordial al entreabrir su psykhé / heautón y permaneciendo en el mediante la práctica de la retención y la concentración del aire y la respiración. Habría que creer, entones, que consistiría en una práctica común de la espiritualidad filosófica que, a causa de la permanencia en ese estado de vacío o pureza meditativa frente a su propia psykhé / heautón, causaría un asombro cercano al éxtasis. Así, anapnoée aér y kháos estarían en una misteriosa e íntima correlación de equilibrio.

VII. Finalmente, refiriéndose al aspecto físico de las Nubes, a Strepsiádes le llama la atención que:

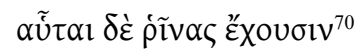

Cabría preguntarse por qué el poeta resalta esta y no otra parte del cuerpo. Independiente de la comicidad que puede provocar una referencia metateatral como ésta, en que evidentemente se refiere a las narices de los coreutas que están disfrazados de nubes $^{71}$, no deja de ser llamativo que sea destacada precisamente la nariz, con la esencial importancia anatómica que tiene para el proceso de la respiración, pues el aire entra por las fosas nasales y, circulando a través de las vías respiratorias, desciende y es contenido en la zona del diafragma, et inversum. Hacia el final de Nubes puede leerse que Sócrates exclama vehementemente:

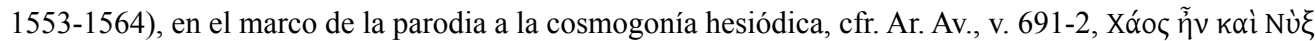

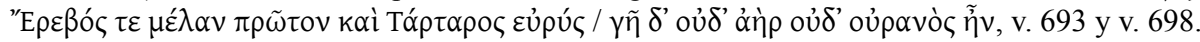

${ }^{67}$ Cfr. Coulon (1923) quien traduce, directamente, Xóos por «Vide», «Vacío».

${ }^{68}$ Xóo ' designa «abismo», «abertura ancha hacia lo profundo» y, en particular, el espacio inmenso y tenebroso que existía antes de las cosas; por extensión, denota la infinitud del espacio (del aire) o la

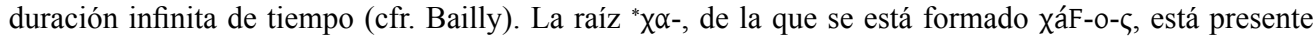

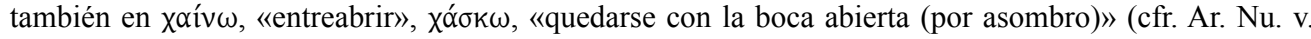

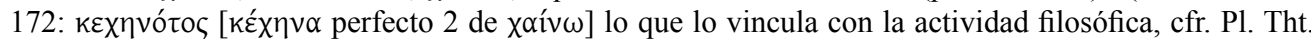

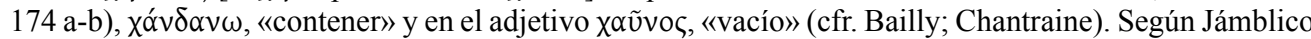
(cfr. Theol. Ar. 6), Xóoৎ es la designación pitagórica de la unidad. Según LSJ, Aristófanes en Nubes lo usa en su acepción de extensión ilimitada de aire (cfr. LSJ, 2), es decir, lo concibe en relación con Aér, por lo que no habría ido más allá de la línea del pensamiento de Anaxímenes y Diógenes de Apolonia, lo que hace insuficiente la extensión de la definición, de acuerdo a lo dicho en el presente trabajo.

${ }^{69} \mathrm{Cfr}$. nota anterior.

${ }^{70}$ Cfr. Ar. Nu., v. 344: «pero estas tienen narices» (la traducción es mía).

${ }^{71}$ Cfr. Cavallero et alli, 2008: 181, nota 4; 187, nota 2. 


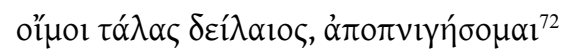

En efecto, Sócrates correría el riesgo de morir de la peor manera (tálas, deílaios), por asfixia (apopnígo, el futuro podría estar dándole un valor de eventualidad), es decir, culminaría su actividad de epimeleteés / phrontistés al no poder practicar ya más el ejercicio espiritual ${ }^{73}$.

VIII. A continuación, algunas conclusiones generales acerca del aspecto espiritual de la actividad que practicara Sócrates en relación con el testimonio de las fuentes:

a) Si bien Aristófanes funde y mezcla doctrinas correspondientes a los physikoí, especialmente de Anaxímenes y de Diógenes de Apolonia, en la composición de su personaje «Sócrates», esto no impide que, a su vez, tuviera noticia de la práctica del ejercicio espiritual socrático y de la importancia que en su desarrollo tenían las técnicas de control y concentración de la respiración, por lo que lo habría también aludido, en su deformación cómica, a la personalidad histórica de Sócrates.

b) A lo largo de la obra de Platón hay muchos lugares donde se mencionan o se aluden las actividades preparativas para alcanzar la verdad, así como las figuras del epimelétés, del phrontistés, del symbouleutés, lo que supone el desarrollo de la actividad espiritual. En los diálogos tempranos, sobre todo en Apología, aparecen con frecuencia testimonios acerca de la práctica, por parte de Sócrates, de las actividades mencionadas, siendo en el Alcibíades I donde se trata casi con exclusividad el tema del epimeleîsthai tês psykhês en tanto transformación de uno mismo como condición para alcanzar la verdad ${ }^{74}$.

c) Nubes, si se examinan con cuidado y detenimiento los pasajes que aluden a estas cuestiones, puede constituirse en un preciado testimonio para iluminar este aspecto un tanto obscurecido de la actividad espiritual socrática que tanta influencia ha tenido, sin embargo, sobre su posteridad ${ }^{75} \mathrm{y}$, asimismo, convertirse en otro documento más de prueba para clarificar el controvertido problema de la historicidad de Sócrates.

\footnotetext{
${ }^{72}$ Cfr. Ar. Nu., v. 1504: «¡iAy de mí, desgraciado, me voy a asfixiar desdichado!!» (la traducción es mía).

${ }^{73}$ Este verso puede presentar cierto paralelismo con el motivo que el Sócrates de Platón expresara

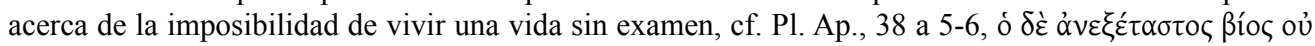

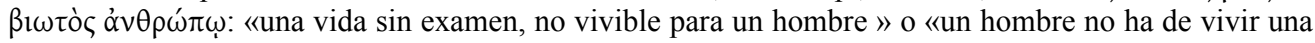
vida sin examen».

${ }^{74}$ Para un estudio detallado de esta problemática en Alcibiades I, cfr. Foucault, 2006: 39-88.

${ }^{75}$ Cfr. Des Places, 1938; Foucault, 2006: 24-29.
} 


\section{BIBLIOGRAFÍA}

\section{Sobre lengua}

Bailly, A., Abrégé du Dictionnaire grec-français. Paris: Hachette.

Berenger Amenós, Jaime, Gramática griega. Barcelona: Bosch.

Chantraine, Pierre, Dictionnaire étymologique de la langue grecque. Histoire des mots. Paris: Klincksieck.

Humbert, Jean, Sintaxe Grecque. Paris: Klincksieck.

Liddell-Scott-Jones (LSJ), Greek-English dictionary. London: Oxford Clarendon Press.

Lukinovich, Alessandra - Rousset, Madeleine, Grammaire de grec ancien. Genéve: Georg Editeur.

Schwyzer, Eduard - Debrunner, Albert, Griechische Grammatik. München: C.H. Beck'sche Verlagsbuchhandlung. Zweiter Band.

Sмyтн, Herbert - Messing, Gordon, Greek Grammar. London: Harvard University Press.

YARZA, Florencio, Diccionario griego-español. Barcelona: Sopena.

\section{General}

Adkins, A. (1970), «Clouds, Mysteries, Socrates and Plato», Antichthon 4: 13-24.

Bernabé, Alberto (1988), Fragmentos presocráticos. Madrid: Alianza.

Burnet, John (1990), «Doctrina socrática del alma», en J. Burnet / A. Taylor, Varia Socratica. México: Universidad Nacional Autónoma de México: 53-118.

Cavallero, Pablo (2007), «La historicidad del Sócrates de Aristófanes y la coincidencia de las fuentes (première partie)», $R E A, 109, \mathrm{n}^{\circ} 2: 449-464$.

- (2008), «La historicidad del Sócrates de Aristófanes y la coincidencia de las fuentes (deuxième partie)», $R E A, 110, \mathrm{n}^{\circ} 1: 5-38$.

Cordero, Néstor (2005), Siendo, se es. La tesis de Parménides. Buenos Aires: Biblos.

CornavacA, Ramón (2008), Presocráticos. Fragmentos I. Buenos Aires: Losada. Edición bilingüe.

Des Places, Édouard (1938), «Socrate directeur de conscience. Étude de vocabulaire», REG 51: 395-402.

Diels, Hermann - Kranz, Walter (1952), Die Fragmente der Vorsokratiker. Berlin: Weidmannshe Verlagsbuchhandlung. Zweiter Band.

Foucault, Michel (2006), La hermenéutica del sujeto. Buenos Aires: FCE.

Frenkel, Diana (2002), «La parodia en Aristófanes», en P. Cavallero et alii, Aristófanes. Riqueza. Buenos Aires: Instituto de Filología Clásica UBA FFyL: 229-240.

Gelzer, M. (1956), «Aristophanes und sein Sokrates», MH 13: 65-93.

Gil FERnÁNDEZ, Luis (1967), Los antiguos y la inspiración poética. Madrid: Guadarrama.

- (2000-2002), «El problema del Sócrates histórico», Excerpta Philologica 10-12: 73-85.

Grimmal, Pierre (2008), Diccionario de mitología Griega y Romana. Buenos Aires: Paidós.

НАDOт, Pierre (1998), ¿Qué es la filosofía antigua?. México: FCE.

- (2006), Ejercicios espirituales y filosofía antigua. Madrid: Siruela.

Havelock, Eric (1972), «The socratic self at it is parodied in Aristophane's Clouds», YCS 22: $1-18$.

Koster, W. (1953), Traité de métrique grecque. Leyde. 
LiÑARes, Lucía (2005), Teogonía. Trabajos y dias. Buenos Aires: Losada. Edición bilingüe.

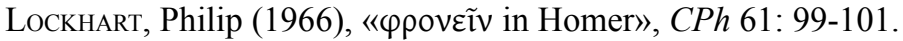

Marianetti, M. C. (1993), «Socratic Mystery-Parody and the issue of asébeia in Aristophane's Clouds», SO 68: 5-31.

Melero, Antonio (1971), «Pythagorica», Emerita 39: 425-433.

Reale, Giovanni, (1998), Platone alla ricerca della sapienza secreta. Rizzoli.

SARRI, Francesco (1973), «Rilettura delle Nuvole di Aristofane come fonte per la conoscenza di Socrate», Rivista di Filosofia Neoscolastica 65: 532-550.

Souto DeliBes, Fernando (1999), «Aristófanes, ¿enemigo de Sócrates?», CFC(egi) 9: 145-153.

\section{Ediciones}

a) Apología

Burnet, John (1973), Platonis Opera, recognovit brevique adnotatione critica instruxit Burnet, J., tomus I. London: Oxford.

b) Nubes

Cantarella, Raffaelle (1954), Aristofane. Le comedie, edizione critica e traduzione a cura di R. Cantarella. Milano: Istituto Editoriale Italiano.

Coulon,Victor - Van Daele, H. (1923), Aristophane. Les Acharniens, Les Cavaliers, Les Nueés, texte établi par V. Coulon et traduit par H. Van Daele. Paris: Belles Lettres.

Dover, K. (1968), Aristophanes Clouds, ed. K. Dover. Oxford Clarendon Press.

Giudorizzi, Giuseppe $\left(2002^{2}\right)$, Aristofane. Le Nuvole, a cura di G. Giudorizzi, introduzione e traduzione di D. Del Corno. Arnaldo Mondadori Editore.

Hall, F. - Geldart, W. (1907), Aristophanes Comoediae, ed. Hall F.W. and Geldart, W. M., vol. 2. Oxford: Clarendon Press.

Rogers, B. (1960), Aristophanes, ed. Rogers, B., Harvard University Press.

\section{Traducciones}

a) Apología

Platón. Apología de Sócrates. Banquete. Fedro. Barcelona: Planeta DeAgostini, 1997 (Apología de Sócrates, trad. J. Calonge Ruiz).

Rossi, Arnaldo (2008), Platón. Apología de Sócrates, traducción y notas A. Rossi. Córdoba: Ediciones del copista. Edición bilingüe.

b) Nubes

Cavallero, Pablo et alii (2008), Nubes de Aristófanes. Edición revisada con estudio introductorio, notas y apéndice. Buenos Aires: Instituto de Filología Clásica UBA FFyL. Edición bilingüe. 